\title{
Current and emerging treatment options for nasopharyngeal carcinoma
}

This article was published in the following Dove Press journal:

OncoTargets and Therapy

19 October 2012

Number of times this article has been viewed

\author{
Daniel E Spratt \\ Nancy Lee \\ Department of Radiation Oncology, \\ Memorial Sloan-Kettering Cancer \\ Center, New York, NY, USA
}

Correspondence: Nancy Lee Department of Radiation Oncology, Memorial Sloan-Kettering Cancer Center, I 275 York Avenue, New York, New York 10021, USA

$\mathrm{Tel}+|2| 2639334 \mid$

Fax + I 2126392417

Email leen2@mskcc.org

\begin{abstract}
In this article, we focus on the current and emerging treatments in nasopharyngeal cancer (NPC). A detailed evolution of the current standard of care, and new techniques and treatment options will be reviewed. Intergroup 0099 established the role for chemoradiotherapy (chemo-RT) in the treatment of nasopharyngeal carcinoma. Multiple randomized Phase III trials have shown the benefit of chemo-RT; however, none of these studies utilized modern radiotherapy (RT) techniques of intensity-modulated radiation therapy (IMRT). IMRT has the ability to deliver high doses of radiation to the target structures while sparing adjacent bystander healthy tissues, and has now become the preferred RT treatment modality. Chemotherapy also has had a shifting paradigm of induction and/or adjuvant chemotherapy combined with RT alone, to the investigation with concurrent chemo-RT. New treatment options including targeted monoclonal antibodies and small molecule tyrosine kinase inhibitors are being studied in NPC. These new biologic therapies have promising in vitro activity for NPC, and emerging clinical studies are beginning to define their role. RT continues to expand its capabilities, and since IMRT and particle therapy, specifically intensity-modulated proton therapy (IMPT), has reports of impressive dosimetric efficacy in-silica. Adaptive RT is attempting to reduce toxicity while maintaining treatment efficacy, and the clinical results are still in their youth. Lastly, EpsteinBarr virus (EBV) DNA has recently been studied for prediction of tumor response and its use as a biomarker is increasingly promising to aid in early detection as well as supplementing the current staging system. RT with or without chemotherapy remains the standard of care for nasopharyngeal carcinoma. Advances in RT technique, timing of chemotherapy, biologically targeted agents, particle therapy, adaptive RT, and the incorporation of EBV DNA as a biomarker may aid in the current and future treatment of nasopharyngeal cancer.
\end{abstract}

Keywords: nasopharyngeal cancer, radiation, chemotherapy, cancer

\section{Introduction}

Nasopharyngeal carcinoma (NPC) is relatively uncommon in most of the world; however, it is among the most common cancer in endemic areas of the globe including Southeast Asia and the Mediterranean. NPC has an incidence of approximately one new case per year per 100,000 in the United States. NPC unlike other squamous cell cancers (SCC) of the head and neck differs in numerous ways. The World Health Organization (WHO) in 1978 classified NPC into three "types," type I is squamous cell carcinoma (SCC), type II is nonkeratinizing squamous cell carcinoma, and type III is nonkeratinizing undifferentiated carcinoma. In the 1991 WHO classification the last two types were combined under the category "nonkeratinizing carcinoma," and the numerical types were eliminated but many simply referred to types I, II, III as now as 
type 1, 2a, and 2b. The current WHO classification system remains similar except for the addition of the basaloid SCC subtype.

WHO type $2 \mathrm{~b}$ (III), or endemic NPC, has been associated with Epstein-Barr virus (EBV), unlike other head and neck cancers. However, WHO type 1 (I) and WHO type 2a (II) have a similar association with tobacco and alcohol use as we see with other head and neck cancer subsites. Other unique characteristics of NPC are its increased radiosensitivity and local control rates, while having high rates of bilateral lymph node involvement and distant metastases.

Secondary to NPC's exquisite radiosensitivity, even with bulky lymphadenopathy, radiotherapy (RT) has become the backbone of treatment. Unlike other head and neck subsites, such as the oral cavity, surgery has little role in NPC due to the high propensity for cervical and lateral retropharyngeal lymph nodes of Rouviére metastasis, making NPC near uniformly unresectable. Surgery's role is primarily limited to radical or selective neck dissections for persistent or recurrent disease after RT.

Chemotherapy also has an important role in the treatment of NPC alongside RT. The Intergroup 0099 study was the first Phase III study to show an overall survival (OS) advantage for the addition of concurrent chemotherapy followed by adjuvant chemotherapy when compared to RT alone for locoregionally advanced NPC. ${ }^{1}$ In doing so it established chemo-RT as the standard of care. Al Sarraf et al published these results in $1998,{ }^{1}$ and nearly 14 years later chemoRT remains the backbone of treatment of locoregionally advanced NPC.

Numerous randomized trials have confirmed the benefit of the addition of chemotherapy to RT, ${ }^{1-5}$ and investigators are seeking methods to address three primary challenges that remain in NPC: (1) reducing toxicity, (2) maintaining excellent local control rates, and (3) decreasing rates of distant metastases. To overcome these challenges the timing and choice of chemotherapeutic agents used are being investigated. In addition, more conformal techniques, including intensitymodulated radiation therapy (IMRT), proton beam therapy, and adaptive treatment planning continue to be studied. As tumor biology is researched, the role of targeted therapies is being investigated in hopes to further tailor personalized therapy for NPC. The goal of the present review is to highlight the current treatment of NPC, and important advances in the treatment of NPC published over the past 10 years.

The association of NPC with EBV is well established. The immunoglobulin A (IgA) to the EBV capsid has been used for screening of NPC; however, the specificity of this technique was poor, and quantification of EBV DNA using PCR became increasingly utilized secondary to the increased specificity for the diagnosis of and monitoring after treatment for NPC. ${ }^{6}$ Furthermore, this technique has been shown to correlate with disease burden, and also with recurrence and survival. Groups have investigated the detailed timing and quantification of EBV DNA and its correlation with tumor response to treatment and OS. ${ }^{7}$ The association of EBV with NPC provides the ability for developing biomarkers not only to enhance early detection, but also to supplement the AJCC TNM staging system.

\section{Evolution of the current standard of care \\ Chemotherapy}

\section{Concurrent chemoradiation}

Locally advanced NPC has a relatively poor prognosis with RT alone, and multiple efforts have been made to improve upon the less than optimal outcomes. RTOG 81-17 was a Phase II trial of local advanced head and neck cancer patients attempting to improve upon RT alone outcomes. ${ }^{8}$ It included 124 patients, of which $22 \%$ were NPC, treated with concurrent chemo-RT. This trial laid the ground work for establishing cisplatin as a safe and effective regimen for advanced cancers of the head and neck. Three years after its initial results, a specific report dedicated to the NPC subset was reported by Al-Sarraf et al. ${ }^{9}$ The results were promising with complete response rates of $89 \%(n=24)$. Seventy percent of patients completed the course of RT and all three cycles of cisplatin, leading to the conclusion that it is an effective and tolerable regimen. This paved the way for multiple Phase III trials to be conducted (see Table 1).

The Intergroup trial 0099/RTOG 88-17 was the first Phase III trial to show an OS benefit for concurrent chemoRT in locoregionally advanced NPC. ${ }^{1}$ The trial was stopped early due to the statistically significant survival benefit. It included Stage III/IV NPC, and the histology types included $25 \%$ WHO I, 35\% WHO II, and 41\% WHO III, which is markedly different from the natural incidence in endemic regions with WHO III making up greater than $90 \%$ of cases. The trial compared RT alone to concurrent cisplatin chemoRT followed by adjuvant cisplatin and 5-FU. The trial was non-IMRT based and utilized wide $2 \mathrm{~cm}$ margins on the gross tumor. The trial reported 3-year outcomes in 1998 with significant improvements in progression-free survival (PFS) (69 vs 24\%) and OS (78 vs 47\%). ${ }^{1}$ Retrospective series published shortly after the Intergroup trial conferred excellent OS rates with the INT 0099 regimen, and further 
Table I Trial design of randomized Phase III trials comparing concurrent chemo-RT to RT alone

\begin{tabular}{|c|c|c|c|c|c|c|}
\hline $\begin{array}{l}\text { Study } \\
\text { (authors or trial) }\end{array}$ & $\mathbf{N}$ & Stage (AJCC) & RT (Gy) & $\begin{array}{l}\text { Concurrent } \\
\text { chemotherapy }\end{array}$ & $\begin{array}{l}\text { Adjuvant } \\
\text { chemotherapy }\end{array}$ & Ref \\
\hline $\begin{array}{l}\text { Al-Sarraf et al } \\
\text { (USA) }\end{array}$ & 147 & III-IV (1992) & 70 & $\begin{array}{l}\text { CDDP } \\
100 \mathrm{mg} / \mathrm{m}^{2} \\
3 \text { cycles }\end{array}$ & $\begin{array}{l}\text { CDDP } 80 \mathrm{mg} / \mathrm{m}^{2}+ \\
5 \text {-FU } 1000 \mathrm{mg} / \mathrm{m}^{2} \\
3 \text { cycles }\end{array}$ & I \\
\hline $\begin{array}{l}\text { Chan et al } \\
\text { (Hong Kong) }\end{array}$ & 350 & $\begin{array}{l}\text { Ho's } N 2 / 3 \text { or } \\
\text { node } \geq 4 \mathrm{~cm}\end{array}$ & $66 \pm 10-20$ Gy boost & $\begin{array}{l}\text { CDDP } \\
40 \mathrm{mg} / \mathrm{m}^{2} \text { weekly }\end{array}$ & NA & 11 \\
\hline $\begin{array}{l}\text { Lin et al } \\
\text { (Taiwan) }\end{array}$ & 284 & III-IV (1992) & $70-74$ & $\begin{array}{l}\text { CDDP } 20 \mathrm{mg} / \mathrm{m}^{2} / \mathrm{d} \times 4 \mathrm{~d} \\
+5 \text {-FU } 400 \mathrm{mg} / \mathrm{m}^{2} / \mathrm{d} \times 4 \mathrm{~d} \\
2 \text { cycles }\end{array}$ & NA & 5 \\
\hline $\begin{array}{l}\text { Kwong et al } \\
\text { (Hong Kong) }\end{array}$ & 219 & $\begin{array}{l}\text { Ho's } \mathrm{T} 3 \text { or } \mathrm{N} 2 / 3 \text { or } \\
\text { node } \geq 4 \mathrm{~cm}\end{array}$ & $66-68 \pm 10$ Gy boost & $\begin{array}{l}\text { UFT } \\
600 \mathrm{mg} \text { daily }\end{array}$ & $\begin{array}{l}\text { CDDP/5FU + VBM } \\
3 \text { cycles }\end{array}$ & 4 \\
\hline $\begin{array}{l}\text { Zhang et al } \\
\text { (Guangzhou) }\end{array}$ & 115 & III-IV (I997) & $70-74$ & $\begin{array}{l}\text { OXAL } \\
70 \mathrm{mg} / \mathrm{m}^{2} / \mathrm{wk}\end{array}$ & NA & 70 \\
\hline $\begin{array}{l}\text { Wee et al } \\
\text { (Singapore) }\end{array}$ & 221 & III-IV (1997) & 70 & $\begin{array}{l}\text { CDDP } \\
25 \mathrm{mg} / \mathrm{m}^{2} / \mathrm{d} \times 4 \mathrm{~d} \\
3 \text { cycles }\end{array}$ & $\begin{array}{l}\text { CDDP } \\
20 \mathrm{mg} / \mathrm{m}^{2} / \mathrm{d} \times 4 \mathrm{~d}+5 \mathrm{FU} \\
1000 \mathrm{mg} / \mathrm{m}^{2} / \mathrm{d} \times 4 \mathrm{~d}\end{array}$ & 3 \\
\hline $\begin{array}{l}\text { Lee et al } \\
\text { (Hong Kong) }\end{array}$ & 348 & $\begin{array}{l}\text { III-IV (1997) } \\
\text { Any T, N2-3 }\end{array}$ & $66 \pm 10$ Gy boost & $\begin{array}{l}\text { CDDP } \\
100 \mathrm{mg} / \mathrm{m}^{2} \\
3 \text { cycles }\end{array}$ & $\begin{array}{l}\text { CDDP } 80 \mathrm{mg} / \mathrm{m}^{2}+ \\
5 \text {-FU } 1000 \mathrm{mg} / \mathrm{m}^{2} \\
3 \text { cycles }\end{array}$ & 2 \\
\hline $\begin{array}{l}\text { Lee et al } \\
\text { (Hong Kong) }\end{array}$ & 189 & $\begin{array}{l}\text { III-IV (1997) } \\
\text { T3-4, N0-I }\end{array}$ & $\begin{array}{l}\geq 66 \text { Gy in } 5 \text { or } 6 \\
\text { fractions/week }\end{array}$ & $\begin{array}{l}\text { CDDP } \\
100 \mathrm{mg} / \mathrm{m}^{2} \\
3 \text { cycles }\end{array}$ & $\begin{array}{l}\text { CDDP } 80 \mathrm{mg} / \mathrm{m}^{2}+ \\
5 \text {-FU } 1000 \mathrm{mg} / \mathrm{m}^{2} \\
3 \text { cycles }\end{array}$ & 13 \\
\hline $\begin{array}{l}\text { Chen et al } \\
\text { (Guangzhou) }\end{array}$ & 316 & III-IV (1997) & 70 & $\begin{array}{l}\text { CDDP } \\
40 \mathrm{mg} / \mathrm{m}^{2} \text { weekly }\end{array}$ & $\begin{array}{l}\text { CDDP } 80 \mathrm{mg} / \mathrm{m}^{2}+ \\
5 \text {-FU } 800 \mathrm{mg} / \mathrm{m}^{2} \\
3 \text { cycles }\end{array}$ & 14 \\
\hline
\end{tabular}

Abbreviations: AJCC, American Joint Committee on Cancer; d, days; wk, weeks; 5-FU, fluorouracil; CDDP, cisplatin; OXAL, oxaliplatin; UFT, uracil and tegafur; VBM, vincristine, bleomycin, methotrexate; RT, radiotherapy.

supported that concurrent cisplatin based chemo-RT should be the standard of care. ${ }^{10}$ However, the Phase III trial was criticized for the low progression-free survival in the RT-alone group, as several retrospective series had shown significantly higher rates of progression-free survival in RT-alone arms in endemic NPC. Due to this it was felt that the results were important but perhaps nonapplicable to non-USA NPC patient populations.

In response to the results of the Intergroup trial and the question of the applicability of the results, several Asian centers initiated their own Phase III trials to test if concurrent chemo-RT provides benefit over RT alone. Tables 1 and 2 highlight the results of nine Phase III trials analyzing concurrent chemo-RT in NPC. All trials used conventional RT technique with opposed lateral fields to a total dose of 66-74 Gy. Chemotherapy generally consisted of platinum-based chemotherapy with the exception of one Hong Kong trial which used uracil and tegafur. The scheduling of chemotherapy was different among trials (see Table 1).

At the Prince of Wales Hospital and Queen Elizabeth Hospitals out of Hong Kong, Chan et al reported on the first Asian Phase III trial in 2002. ${ }^{11}$ The trial aimed to test the benefit of weekly cisplatin given concurrently with RT versus
RT alone. Only $1 \%$ were WHO I histology, more representative to endemic NPC. The first reported data of 2-year outcomes showed no significant difference in PFS (76\% vs $69 \%$ ), their primary outcome. ${ }^{11}$ However, their updated 5-year results in 2005 reported both a significant improvement in PFS, but also a trend in OS (70\% vs 59\%), and a significant OS in stage T3/T4 stage $(P=0.013) .^{12}$

Shortly after the initial results from Hong Kong, Lin et al from Taiwan published their 5-year results showing both significant improvements in PFS and OS for concurrent chemoRT over RT alone. ${ }^{5}$ Since then, Kwong et al from Hong Kong, ${ }^{4}$ Wee et al from Singapore, ${ }^{3}$ and Lee et al from Hong Kong ${ }^{2}$ have published their results of other Phase III trials, all of which demonstrate an advantage to concurrent chemo-RT in locally advanced NPC. In addition, Lee et al from Hong Kong published the results in 2006 from their NPC-9902 which was opened at the same time as the NPC-9901. ${ }^{13}$ Unfortunately the 9902 trial was closed early due to slow accrual and includes only 189 patients. It aimed to look at only advanced T-stage disease while analyzing if accelerated RT could add further benefit to concurrent standard fractionated chemoRT. Preliminary results with 3-year outcomes on failure-free survival (FFS) rates with RT alone 70\%, accelerated-RT alone 
Table 2 Outcomes of randomized Phase III trials comparing concurrent chemo-RT to RT alone

\begin{tabular}{|c|c|c|c|c|c|c|c|}
\hline $\begin{array}{l}\text { Study } \\
\text { (authors or trial) }\end{array}$ & $\begin{array}{l}\text { Median follow-up } \\
\text { (months) }\end{array}$ & $\begin{array}{l}\text { Time point } \\
\text { (years) }\end{array}$ & Treatment arm & OS (\%) & PFS (\%) & DMFS (\%) & Ref \\
\hline Al-Sarraf et al & 60 & 5 & $\mathrm{RT}$ & 37 & 29 & & 1 \\
\hline \multirow[t]{2}{*}{ (USA) } & & & Chemo-RT & 67 & 58 & & \\
\hline & & & & $P=0.001$ & $P<0.001$ & & \\
\hline Chan et al & 66 & 5 & $\mathrm{RT}$ & 80 & 52 & & 11 \\
\hline \multirow[t]{2}{*}{ (Hong Kong) } & & & Chemo-RT & 90 & 60 & & \\
\hline & & & & $P=0.049$ & $P=0.16$ & & \\
\hline Lin et al & 65 & 5 & RT & 54 & 53 & 70 & 5 \\
\hline \multirow[t]{2}{*}{ (Taiwan) } & & & Chemo-RT & 72 & 72 & 79 & \\
\hline & & & & $P=0.002$ & $P=0.001$ & $P=0.058$ & \\
\hline Kwong et al & 37 & 3 & RT & 77 & 58 & 71 & 4 \\
\hline \multirow[t]{2}{*}{ (Hong Kong) } & & & Chemo-RT & 87 & 69 & 85 & \\
\hline & & & & $P=0.06$ & $P=0.14$ & $P=0.026$ & \\
\hline Zhang et al & 24 & 2 & $\mathrm{RT}$ & 77 & 83 & 80 & \\
\hline \multirow[t]{2}{*}{ (Guangzhou) } & & & Chemo-RT & 100 & 96 & 92 & 70 \\
\hline & & & & $P=0.01$ & $P=0.02$ & $P=0.02$ & \\
\hline Wee et al & 38 & 2 & $\mathrm{RT}$ & 49 & 46 & & 3 \\
\hline \multirow[t]{2}{*}{ (Singapore) } & & & Chemo-RT & 67 & 59 & & \\
\hline & & & & $P=0.008$ & $P=0.032$ & & \\
\hline Lee et al & 25 & 3 & $\mathrm{RT}$ & 78 & 62 & 73 & \\
\hline \multirow[t]{2}{*}{ (Hong Kong) } & & & Chemo-RT & 78 & 72 & 76 & 2 \\
\hline & & & & $P=0.97$ & $P=0.027$ & $P=0.47$ & \\
\hline Lee et al & 35 & 3 & $\mathrm{RT}$ & 83 & 68 & 81 & \\
\hline \multirow[t]{4}{*}{ (Hong Kong) } & & & Chemo-RT & 87 & 73 & 89 & \\
\hline & & & $\mathrm{A}-\mathrm{RT}$ & 73 & 63 & 77 & \\
\hline & & & Chemo-A-RT & 88 & 88 & 97 & 13 \\
\hline & & & & $P=0.65$ & $P=0.061$ & $P=0.029$ & \\
\hline Chen et al & 29 & 2 & $\mathrm{RT}$ & 80 & 73 & 79 & \\
\hline \multirow[t]{2}{*}{ (Guangzhou) } & & & Chemo-RT & 90 & 85 & 87 & 14 \\
\hline & & & & $P=0.003$ & $P=0.001$ & $P=0.024$ & \\
\hline
\end{tabular}

Abbreviations: A-RT, accelerated radiotherapy; DMFS, distant metastases-free survival; OS, overall survival; PFS, progression-free survival; RT, radiotherapy.

63\%, chemo-RT (standard fractionation) 74\%, and chemoaccelerated-RT 94\%, with a significant difference between RT alone and chemo-accelerated-RT $(P=0.008)$. Interestinglys, there was no significant difference between accelerated-RT alone and chemo-RT (standard fractionation). However, late toxicities were most severe in the chemo-accelerated-RT $\operatorname{arm}(P=0.05)$. Most recently, Chen et al from Guangzhou published their 2-year results with significant improvements in OS, PFS, and distant metastasis-free survival (DMFS). ${ }^{14}$ Tables 1 and 2 outline the trial design and outcomes of these nine Phase III trials. This trial focused on Chinese stage II patients, which is equivalent to AJCC stage II and III.

\section{Induction chemotherapy}

Similar to RT-alone being the control arm when compared to concurrent chemo-RT, neoadjuvant or induction chemotherapy followed by RT was also compared to RT-alone arms. Five randomized trials have been conducted to evaluate the role of induction chemotherapy when compared to RT alone (Table 3). Chan et al from the Prince of Wales Hospital in Hong Kong first reported their 2-year results in $1995 .{ }^{15}$ They found no significant difference in disease-free survival (DFS), OS, local-regional control (LRC), or distant metastases (DM). One year later the International Nasopharynx Cancer Study Group published their 2-year outcomes showing an improvement in DFS, but not OS or LRC. ${ }^{16}$ Treatment related deaths were higher in the induction arm (8\% vs 1\%). Ma et al from Guangzhou ${ }^{17}$ and the Asian-Oceanic Clinical Oncology Association (AOCOA $)^{18}$ went on to publish independent Phase III trials comparing induction chemotherapy followed by RT to RT alone. A pooled analysis of these two trials was eventually published in 2005 with 5-year outcomes. ${ }^{19}$ Induction chemotherapy showed a reduction in relapse-free survival (RFS) and disease-specific survival (DSS) rates. There was no significant difference in OS or treatment failure patterns. The most recent of the Phase III trials was published in 2002 
Table 3 Randomized Phase III trials of induction chemotherapy and RT compared to RT alone

\begin{tabular}{|c|c|c|c|c|c|c|c|c|c|}
\hline $\begin{array}{l}\text { Study } \\
\text { (authors or trial) }\end{array}$ & $\begin{array}{l}\text { Median follow-up } \\
\text { (months) }\end{array}$ & $\begin{array}{l}\text { Time point } \\
\text { (years) }\end{array}$ & $\begin{array}{l}\text { Treatment } \\
\text { arm }\end{array}$ & $\mathbf{N}$ & Regimen & $\begin{array}{l}\text { OS } \\
\text { (\%) }\end{array}$ & $\begin{array}{l}\text { PFS } \\
\text { (\%) }\end{array}$ & $\begin{array}{l}\text { DMFS } \\
\text { (\%) }\end{array}$ & Ref \\
\hline Chan et al & 28.5 & 2 & $\mathrm{RT}$ & 40 & 66 Gy \pm 7.5 Gy boost & 80 & 72 & 76 & 15 \\
\hline \multirow[t]{5}{*}{ (Hong Kong) } & & & Induction-RT- & 37 & CDDP $100 \mathrm{mg} / \mathrm{m}^{2}+$ & 80 & 68 & 78 & \\
\hline & & & adjuvant chemo & & $5-\mathrm{FU} 1000 \mathrm{mg} / \mathrm{m}^{2}$ & & & & \\
\hline & & & & & 2 cycles induction & & & & \\
\hline & & & & & 4 cycles adjuvant & & & & \\
\hline & & & & & & NS & NS & NS & \\
\hline International Nasopharynx & 49 & 5 & RT & 168 & $70 \mathrm{~Gy}$ & 46 & 30 & & 16 \\
\hline Cancer Study Group & & & Induction-RT & $17 \mid$ & BEC & 40 & 40 & & \\
\hline \multirow[t]{2}{*}{ VUMCA I } & & & & & 3 cycles & & & & \\
\hline & & & & & & NS & $P<0.01$ & SS & \\
\hline Chua et al & 30 & 3 & RT & 152 & 66-74 Gy & 71 & 42 & & 18 \\
\hline \multirow[t]{4}{*}{$(\mathrm{AOCOA})$} & & & Induction-RT & 134 & CDDP $60 \mathrm{mg} / \mathrm{m}^{2}+$ & 78 & 48 & & \\
\hline & & & & & Epi 110 mg/m² & & & & \\
\hline & & & & & $2-3$ cycles & & & & \\
\hline & & & & & & NS & NS & NS & \\
\hline \multirow{6}{*}{$\begin{array}{l}\text { Ma et al } \\
\text { (Guangzhou) }\end{array}$} & 62 & 5 & RT & 225 & $68-72 \mathrm{~Gy} \pm 10-14 \mathrm{~Gy}$ & 56 & 49 & 75 & 17 \\
\hline & & & & & boost w/EBRT or 20-24 & & & & \\
\hline & & & & & Gy boost w/HDR & & & & \\
\hline & & & Induction-RT & 224 & CDDP, 5-FU, Bleo & 63 & 59 & 79 & \\
\hline & & & & & $2-3$ cycles & & & & \\
\hline & & & & & & NS & $P=0.05$ & NS & \\
\hline Hareyama et al & 49 & 5 & RT & 40 & $66-68 \mathrm{~Gy}$ & 48 & 43 & 56 & 20 \\
\hline \multirow[t]{4}{*}{ (Japan) } & & & Induction-RT & 40 & CDDP $80 \mathrm{mg} / \mathrm{m}^{2}+$ & 60 & 55 & 74 & \\
\hline & & & & & $5-F U ~ 800 \mathrm{mg} / \mathrm{m}^{2}$ & & & & \\
\hline & & & & & 2 cycles & & & & \\
\hline & & & & & & NS & NS & NS & \\
\hline
\end{tabular}

Abbreviations: 5-FU, 5-fluorouracil; AOCOA, Asian-Oceanian Clinical Oncology Association; BEC, bleomycin, epirubicin, and cisplatin; Bleo, bleomycin; CDDP, cisplatin; EBRT, External Beam Radiotherapy; Epi, epirubicin; Gy, Gray; HDR, high dose rate; OS, overall survival; PFS, progression-free survival; PWH, Prince of Wales Hospital; RT, ratiotheraphy; NS, not significant; DMFS; distant metastases-free survival.

by Hareyama et al and found no difference in DFS or OS with the addition of induction chemotherapy to RT. ${ }^{20}$

Shortly after the initial results of the initial induction chemotherapy trials were reported, the INT0099 and the promising benefit of concurrent chemo-RT, interest in induction chemotherapy diminished. Oncologists felt that if chemotherapy was to be given concurrently rather than sequentially, had the more consistent and impressive outcomes, and became and remains the standard of care.

Logically, the question was then asked of what induction chemotherapy may add to concurrent chemo-RT. Numerous phase II trials have reported their outcomes, with no Phase III trials published to date specifically for NPC. In 2009, Hui et al reported the results of their Phase II trials out of Hong Kong with 3-year outcomes showing a significant improvement in OS (94\% vs 68\%), but nonsignificant change in PFS (88\% vs 59\%). ${ }^{21}$ The Hellenic Cooperative Oncology Group recently published the results of their Phase II trial comparing induction chemotherapy with cisplatin, epirubicin, and paclitaxel followed by concurrent chemo-RT with cisplatin, versus concurrent chemo-RT alone. ${ }^{22}$ Overall and complete response rates were similar between arms, and there was no significant difference between 3-year PFS or OS rates. The role of induction chemotherapy in addition to concurrent chemotherapy remains to be defined and is currently not the standard of care. There are three on-going Phase III trials (Hong Kong, France, and Singapore) that will definitely address the role of induction chemotherapy prior to CCRT.

\section{Adjuvant chemotherapy}

Similar to induction chemotherapy, initially adjuvant chemotherapy was compared to RT alone arms. Multiple Phase III trials were published from the Italian NRC, ${ }^{23}$ Taiwan $\mathrm{COG},{ }^{24}$ and, most recently, Queen Mary hospital in Hong Kong, ${ }^{4}$ all showing no significant benefit in OS or RFS. Hence, adjuvant chemotherapy, despite its use in the landmark Intergroup trial, has not been adopted as a part of the standard of care without the use of concurrent chemotherapy.

Again similar to induction chemotherapy, Phase II trials have reported on the addition of adjuvant chemotherapy to concurrent chemo-RT. ${ }^{25} \mathrm{Hu}$ et al recently published their data on 54 locally advanced NPC patients treated with taxane- 
based chemo-RT treated to $70 \mathrm{~Gy}$, followed by taxane-based chemotherapy. ${ }^{25}$ Three-year PFS was $69 \%$, and OS was $76 \%$. Maturation of studies such as this will help gain an understanding to what adjuvant therapy truly adds to concurrent chemo-RT.

Due to the INT0099 containing adjuvant chemotherapy as part of the chemoradiation regimen, one can argue that it should be a part of the standard of care. To test this question, Chen et al conducted a Phase III multicenter randomized trials with concurrent chemo-RT with or without adjuvant chemotherapy in advanced NPC. ${ }^{26}$ Patients were either stage III or IV (nonmetastatic) and the study recently reported outcomes showing that the 251 patients in the concurrent plus adjuvant chemotherapy arm had failure-free survival rate of $86 \%$, while the 257 patients without adjuvant chemotherapy had a failure-free survival rate of $84 \%(P=0.13)$. Longer follow-up is needed to definitively answer the question of what adjuvant chemotherapy adds to concurrent chemo-RT; however, the results from this study do not suggest a significant benefit. Furthermore, the survival curves do appear to separate and $\sim 20 \%$ of patients randomized to adjuvant chemotherapy did not receive chemotherapy. Furthermore, this trial was not designed as a noninferiority trial against the current standard of the US Intergroup 0099 trial.

Despite the Al-Sarraf trial giving adjuvant chemotherapy, one can argue that within the trial only $55 \%$ of the patients completed adjuvant chemotherapy, and hence compliance and toxicity are issues. ${ }^{1}$ The Wee trial confirmed these findings. ${ }^{3}$ Hence, the question must be posed if adjuvant chemotherapy simply moves up the curve to more benefit with more toxicity and no absolute therapeutic gain. As mentioned above, the Chen trial attempted to answer this question; however, it was not designed as a noninferiority trial. ${ }^{26}$ The use of adjuvant chemotherapy remains debatable, but it should be noted that the Lin trial from Taiwan showed that giving concurrent chemo-RT alone was insufficient for high risk patients, so perhaps in high risk patients it may play a role..$^{5}$

\section{Meta-analyses}

Four meta-analyses investigating the incorporation of chemotherapy with RT in NPC have been published in the English language. ${ }^{27-30}$ All demonstrated that chemotherapy was beneficial over RT alone, with the primary benefit seen with concurrent chemotherapy scheduling. The Meta-Analysis of Chemotherapy in Nasopharynx Carcinoma (MAC-NPC) ${ }^{31}$ meta-analysis performed through the Cochrane Review system was the only meta-analysis that individual patient data from eight randomized trials was analyzed. Of note, one trial's data was counted twice due to its $2 \times 2$ design so data was actually analyzed from a total of 1975 patients. This study found that chemotherapy provided a $6 \%$ absolute survival benefit at 5 years, and an event-free survival benefit of $10 \%$ at 5 years. Importantly, timing was highly significant with OS $(P=0.005)$, with concurrent chemo-RT providing the majority of the benefit in survival.

\section{Radiation therapy}

\section{Conventional and three-dimensional conformal treatment}

Nearly all of the trials mentioned to this point have solely used two- or three-dimensional (2D or $3 \mathrm{D}$ ) radiation treatment planning and delivery. The head and neck has arguably the most critical structures, and, if not carefully avoided, can lead to intense acute side effects, as well as severe late toxicities that greatly impact quality of life. Due to both the anatomy, and the routes of spread of NPC, the nasopharynx of all of the head and neck cancers has a vast number of bystander structures that will be treated if using conventional techniques. Between the base of skull for the high propensity for perineural invasion, and bilateral cervical lymph nodes including retropharyngeal and level 5 lymph nodes, conventional RT puts the optic apparatus, cochlea, parotid and submandibular glands, spinal cord/brainstem, oral cavity, larynx, and pharyngeal constrictors all at risk of significant dose and toxicity. Secondary to the close proximity of the normal structures, toxicity is often debilitating, and the INT0099 trial reported grade 3 toxicities at 55\% and grade 4 at $21 \%$ with conventional RT techniques. ${ }^{1}$

Not only is their concern for toxicity, but, because of these dose-limiting structures, poor target coverage can become a concern. Ways to improve optimal dose to the target volume while avoiding as many of the organs at risk became paramount in advancing the treatment of NPC. IMRT was the first large step in the advances in radiation oncology that aimed to fill this goal.

\section{IMRT}

IMRT was employed to help overcome treating the nonconformal volumes of NPC as well as help limit dose to the numerous close proximity bystander structures. Proof of principal of the superiority of IMRT can be found in numerous dosimetric analyses comparing IMRT to both 2D and 3D techniques. Dosimetrically, improved tumor coverage and avoidance of organs at risk created much excitement. $^{31-34}$ 
Xerostomia is one of the most immediate and chronic toxicities of NPC treatment..$^{35}$ Memorial Sloan-Kettering published their experience with the treatment of NPC using IMRT. They found that long-term xerostomia $>1$ year after treatment were, no xerostomia in $26 \%, 42 \%$ Grade $1,32 \%$ Grade 2, and no Grade $3 .{ }^{35}$ Lee et al published the UCSF experience with IMRT for NPC, and at 2 years out from treatment, $66 \%$ had no xerostomia, $32 \%$ with Grade 1 , and only 1 patient of 41 evaluable had grade $2 .{ }^{36} \mathrm{~A}$ randomized trial has been reported by Pow et al specifically on xerostomia and quality of life (QOL) after IMRT when compared to conventional RT. ${ }^{37}$ They found that IMRT had significantly faster recovery time of stimulated salivary flow compared to conventional RT. Furthermore, QOL related to xerostomia was also significantly improved in the IMRT treatment arm.

The benefit of IMRT has not solely been limited to improved toxicity and QOL. As seen in Table 4, multiple institutions have published their experience with the treatment of NPC using IMRT, and report excellent tumor control rates. UCSF published a large retrospective series on definitive treatment for NPC using IMRT. ${ }^{36}$ The 4-year local progression-free survival (LPFS) and regional progressionfree (RPF) rates reported were $97 \%$ and $98 \%$, respectively. Two years after this report, the Queen Mary Hospital ${ }^{38}$ and
Prince of Wales Hospital, ${ }^{32}$ both in Hong Kong, published their experiences with IMRT in NPC with similar results to UCSF. MSKCC published their results with IMRT in $2006 .{ }^{35}$ The 3-year local control rate was $91 \%$, regional control $93 \%$, PFS $67 \%$, and OS 83\%. Early T-stage (T1 or T2) tumors had $100 \%$ local control, while T3 and T4 disease had $83 \%$ local control rates.

The landmark Phase II trial though that showed the feasibility of treating NPC with IMRT among multiple US institutions was the RTOG 02-25 trial. ${ }^{39}$ The results were recently published in 2009 on 68 patients with Stage I-IVb NPC. Ninety-four percent were WHO II and III. IMRT was delivered using what is now considered the standard fractionation schedule of $70 \mathrm{~Gy}$ in $2.12 \mathrm{~Gy}$ fractions. Node positive or high T-stage disease received both concurrent as well as adjuvant chemotherapy. Two-year outcomes were reported with LC of $93 \%$, LRC $89 \%$, DMFR $85 \%$, PFS $93 \%$, and OS $80 \%$. Xerostomia was reported at 1 -year posttreatment with $13.5 \%$ with grade 2 , two patients with grade 3 , and none with grade 4 .

Due to the ability to spare normal structures and improve dosing to the tumor volume, IMRT has become part of the standard of care in the treatment of NPC, and is the "preferred technique" according to the National Comprehensive Cancer Network guidelines (www.nccn.org).

Table 4 Outcomes on IMRT for NPC

\begin{tabular}{|c|c|c|c|c|c|c|c|c|}
\hline $\begin{array}{l}\text { Study } \\
\text { (authors or trial) }\end{array}$ & $\mathbf{N}$ & $\begin{array}{l}\text { Stage III/IV } \\
\text { (\%) (AJCC) }\end{array}$ & $\begin{array}{l}\text { Time point } \\
\text { (years) }\end{array}$ & OS (\%) & LC (\%) & RC (\%) & DMFS (\%) & Ref \\
\hline $\begin{array}{l}\text { Lee et al } \\
\text { (UCSF) }\end{array}$ & 67 & 70 & 4 & 88 & 97 & 98 & 66 & 36 \\
\hline $\begin{array}{l}\text { Kam et al } \\
\text { (Hong Kong) }\end{array}$ & 63 & 57 & 3 & 90 & 92 & 98 & 79 & 71 \\
\hline $\begin{array}{l}\text { Kwong et al } \\
\text { (Hong Kong) }\end{array}$ & 33 & 3 & 3 & 100 & 100 & 92 & 100 & 38 \\
\hline $\begin{array}{l}\text { Wolden et al } \\
\text { (MSKCC) }\end{array}$ & 74 & 77 & 3 & 83 & 91 & 93 & 78 & 35 \\
\hline $\begin{array}{l}\text { Lee et al } \\
\text { (RTOG 02-25) }\end{array}$ & 68 & 59 & 2 & 80 & 93 & 91 & 85 & 39 \\
\hline $\begin{array}{l}\text { Tham et al } \\
\text { (Singapore) }\end{array}$ & 195 & 63 & 3 & 94 & 90 & & 89 & 72 \\
\hline $\begin{array}{l}\text { Lin et al } \\
\text { (Fujian) }\end{array}$ & 323 & 80 & 3 & 90 & 95 & 98 & 90 & 73 \\
\hline $\begin{array}{l}\text { Wong et al } \\
\text { (Hong Kong) }\end{array}$ & 175 & 35 & 3 & 87 & 94 & 93 & 87 & 74 \\
\hline $\begin{array}{l}\text { Ng et al } \\
\text { (Hong Kong) }\end{array}$ & 193 & 61 & 2 & 92 & 95 & 96 & 90 & 75 \\
\hline $\begin{array}{l}\text { Xiao et al } \\
\text { (Guangzhou) }\end{array}$ & 81 & 100 & 5 & 75 & 95 & & & 76 \\
\hline $\begin{array}{l}\text { Lai et al } \\
\text { (Guangzhou) }\end{array}$ & 512 & 52 & 5 & & 93 & 97 & 84 & 77 \\
\hline
\end{tabular}

Abbreviations: AJCC, American Joint Committee on Cancer; DMFS, distant metastasis-free survival. LC, local control; MSKCC, Memorial Sloan-Kettering Cancer Center; OS, overall survival; RC, regional control; RTOG, Radiation Therapy Oncology Group; UCSF, University of California San Francisco; IMRT, intensity-modulated radiation therapy; NPC, nasopharyndeal carcinoma. 


\section{Emerging treatments \\ Biologic target therapy}

Cetuximab, a monoclonal antibody that inhibits the epidermal growth factor receptor (EGFR), has established a role in the treatment of squamous cell cancer of the head and neck cancer. ${ }^{40}$ Its use specifically for NPC, however, is less well defined. Multiple Phase II trials have reported their results with either monotherpay with and EGFR inhibitor, or in combination with chemotherapy. Cetuximab has been studied in combination with carboplatin in a multicenter Phase II trial for recurrent or metastatic NPC. ${ }^{41}$ Of the 60 patients enrolled, $12 \%$ had a partial response, $48 \%$ with stable disease, and $38 \%$ with progressive disease. Overall the study showed that despite these patients already being treated with standard cisplatin based chemotherapy, a modest response can still be gained from further treatment in the recurrent setting. It is difficult though to assess the benefit gained specifically by cetuximab as chemotherapy was also given.

A more recent Phase II trial with cetuximab, weekly cisplatin, and IMRT for locally advanced NPC was reported. ${ }^{42}$ The 2-year PFS was $86.5 \%$, and the toxicity rates were high with $87 \%$ of patients experiencing grade $3-4$ mucositis and $33 \%$ requiring nasogastric feeding. When comparing these results to the RTOG $02-25$, cetuximab likely is not adding any noticeable benefit, at least at 2 years. Longer follow-up will help define the role of cetuximab for NPC.

Other small molecule inhibitors, including two other EGR inhibitors, gefitinib and erlotinib, as well as the multi-tyrosine kinase inhibitor sorafenib, have also been investigated in NPC. ${ }^{43}$ The results of these trials have yet to show substantial benefits, but further investigation is necessary to define their role and potential utility in the treatment of NPC. Currently, nimotuzumab, a humanized monoclonal antibody against EGFR, is under investigation with chemo-RT for locally advanced NPC.

Vascular endothelial growth factor (VEGF) is another target that is being investigated for NPC, both in vitro and in vivo. ${ }^{44,45}$ VEGF has been found to be overexpressed in $67 \%$ of NPC, and in EBV-positive tumors has been linked to higher rates of death, recurrence, and lymph node involement. ${ }^{44}$ Bevacizumab, a monoclonal antibody that inhibits VEGF, is currently being investigated with cisplatin based chemo-RT in a Phase II trial, RTOG 06-15. Lee et al recently reported their results with concurrent cisplatin and bevacizumab with RT delivered via IMRT. ${ }^{46}$ The authors reported that the addition of bevacizumab is feasible with no grade 3 or 4 hemorrhagic events, but $20 \%$ of patients had a grade 1-2 hemorrhage.

\section{Proton beam RT}

The perfect RT treatment modality would be to fully target the radiation solely to the tumor with no dose given to surrounding normal tissues. Current techniques with photons have made large strides in improving the therapeutic ratio; however, certain properties are intrinsic to photon-based RT. The primary limitation to photon beams are the inevitable entry and exit dose. To reduce this phenomenon multiple beams from various angles are now employed using IMRT to decrease the percentage of the total dose to any point not involved in the planning target volume.

Proton-beam RT, like other charged-particle RT, has unique physical properties that have a potential benefit in the treatment of a variety of tumors. Whereas photons deposit their dose close to the surface and continually reduce dose over depth, protons deposit the majority of their dose within the Bragg peak. This peak is relatively small in regards to depth and techniques that spread the Bragg peak are needed to cover tumor volumes. Not only is there a lower dose upon entry, there is significantly lower exit dose beyond the tumor. Despite the physical advantages of protons, there has been a struggle to clinically translate this benefit in regards to reduced toxicity in most disease sites.

The same rationale for the adoption of IMRT for NPC secondary to the complex anatomy and adjacent critical structures, proton-beam RT was introduced to attempt to further the gains IMRT provided. Initially in-silico planning studies were performed for NPC to provide one step beyond a purely theoretical advantage of proton beam RT. Two modern in-silico studies ${ }^{47-49}$ and one report from the late $1980 \mathrm{~s}^{48}$ have been performed. The modern studies compared IMRT (one using tomotherapy) with intensity-modulated proton therapy (IMPT), while the older report compared 3D-CRT to mixed photon-proton RT. Overall, the studies reported that tumor coverage and the conformity of the plan were improved with the proton arms. Furthermore, it was shown that dose escalation could be achieved to the tumor volume without exceeding bystander tissue constraints. All of the studies reported a marked reduction in dose to critical normal structures in these in-silico studies. Studies such as these have been reported on numerous head and neck cancer subsites; however, their clinical benefit remains to be as clear..$^{50}$ The question remains, and is currently the focus of national controversy, whether the theoretic advantage of proton beam RT can translate into a clinical benefit.

To help answer this question for NPC, Massachusetts General Hospital initiated a Phase II trial in 2007 with proton-beam RT with cisplatin-based chemotherapy. The 
study aims to determine the efficacy of toxicity reduction, both acute and later toxicity, as well as if sparing of normal tissue will translate into improved quality of life (see trial: NCT00592501). Furthermore, the University of Florida also initiated in 2008 a nonrandomized study utilizing proton beam RT for NPC. Chemotherapy will be given based on stage of disease, and the primary outcome will be rates of xerostomia (see trial: NCT00797290).

\section{Adaptive RT}

When viewing a patient's anatomy from an isocentric perspective one can expect numerous changes to occur throughout treatment. Chemo-RT changes the anatomy in two primary ways: (1) tumor volume itself is often reduced, both primary and nodal volumes; and (2) patients lose weight, often $>$ $15 \mathrm{lbs}$ over the $\sim 7$ weeks of treatment. Depending on the degree of these two changes, organs at risk will be displaced into the planning target volume creating unexpected and unnecessary dosing to healthy tissue. Bhide et al has shown this occurs primarily in the first 2 weeks during the treatment of head and neck cancer using IMRT. ${ }^{51}$

Assuming the margins used for creating the planning target are adequate $100 \%$ of the time for the anatomic changes that occur during treatment, then geographic miss of the tumor should not occur. However, with increasing utilization of image-guided RT, margin diameter has decreased, and the potential for inadequate tumor coverage begins to become a possibility. To overcome these challenges groups have investigated replanning patients during their RT treatment course. This entails resimulating the patient, and if significant deviations have occurred from the original plan, a new plan must be generated. Groups have reported their recommendation on when and how to implement adaptive RT, however patient selection remains a difficult challenge.

In 2011, Zhao et al reported their results from a retrospective study of 33 patients with NPC who underwent adaptive RT with replanning. ${ }^{52}$ The control arm consisted of 66 matched patients treated with their original IMRT plan throughout the entirety of treatment. Most of the patients in the adaptive RT arm were replanned between 2 and 3 weeks of treatment. Similar to the report from Bhide et al, ${ }^{51} \mathrm{Zhao}$ also found significant reductions in gross tumor volume, both primary and nodal volumes. ${ }^{52}$ Three-year outcomes were reported and found significantly improved local relapsefree survival in patients with T3-4 disease treated with adaptive RT when compared to the control arm. In addition there were reductions in toxicity rates, with significant reduction in xerostomia with adaptive RT.

\section{EBV DNA}

Since the 1970s, anti-EBV antibodies have been investigated as potential biomarkers for NPC. ${ }^{53}$ However, despite promising results from some studies reporting that higher levels of EBV DNA-ase neutralizing antibody correlate with worse $\mathrm{OS},{ }^{54}$ others did not find such promising results. It has been shown that patients with active tumor have an increased amount of select anti-EBV antibodies than controls. ${ }^{53}$ However, others have shown that even after treatment and with patients having no evidence of disease, EBV antibody levels have poor predictive value for disease monitoring secondary to the titers never returning to the normal range. ${ }^{55,56}$ In addition, at least two studies showed that select antibodies including viral capsid IgA and IgG are not prognostic, and other groups have found that EBV antibody titers are simply not prognostic regarding NPC outcomes, making the matter more complex. ${ }^{57-60}$

The advent of modern-day real time quantitative PCR has resurged the investigation of more specific EBV biomarkers in NPC. Studies have shown that the sensitivity and specificity are both over 90\% using EBV DNA techniques, and Twu et al showed that EBV DNA was more prognostic than anti-EBV antibodies. ${ }^{59,61,62}$ Numerous groups have confirmed this and have found that plasma EBV DNA levels correlate with TNM staging, tumor control, and OS..$^{7,63-67}$ Due to the power that modern-day biology has allowed, EBV DNA has the potential to impact treatment decision making. As was the hope for anti-EBV antibody titers, EBV DNA levels have also been shown to be very sensitive for monitoring posttreatment recurrence, and some have shown that it is even more accurate than FDG-PET for survelliance. ${ }^{68} \mathrm{~A}$ current trial is underway in Hong Kong incorporating EBV DNA as part of the design in the treatment of NPC. Similarly, RTOG will open the next Phase II-III study aimed to incorporate EBV DNA as part of the treatment design.

\section{Other modalities on the forefront}

Other methods of improving the therapeutic ratio are also being investigated that include new imaging techniques to identify more hypoxic regions of the tumor, to novel recombinant adenovirus-p53 intratumoral injections that are exciting new areas of research. ${ }^{69}$ This review will not delve into these topics, but nonetheless it is clear that the treatment of NPC continues to push new limits.

\section{Summary of emerging treatments}

The three challenges discussed in the introduction for the treatment of NPC, of decreasing toxicity, maintaining 
excellent local control rates, and reducing distant metastasis, are at the forefront of current investigational therapies. Biological therapy, proton-beam RT, and adaptive RT each address these challenges in their own unique method and only time and further research will help elucidate their benefit for NPC.

\section{Expert opinion and conclusions}

Despite multiple randomized studies since the US Intergroup 0099 trial, concurrent chemo-RT followed by adjuvant chemotherapy is still the standard of care for locoregionally advanced nasopharyngeal cancer. Intensity-modulated radiation therapy should be offered to all patients to improve locoregional control as well as minimizing toxicity. Furthermore, with the incorporation of EBV DNA in the current NPC treatment design, efforts should focus on omitting adjuvant chemotherapy for those patients not at risk for failure after concurrent chemo-RT. For those patients who are at risk for failure based on persistent and elevated EBV DNA levels, efforts should be focused on finding alternative adjuvant chemotherapy combinations to improve treatment outcomes.

\section{Disclosure}

The authors report no financial support or conflicts of interest in this work.

\section{References}

1. Al-Sarraf M, LeBlanc M, Giri PG, et al. Chemoradiotherapy versus radiotherapy in patients with advanced nasopharyngeal cancer: phase III randomized Intergroup study 0099. J Clin Oncol. 1998;16: 1310-1317.

2. Lee AW, Lau WH, Tung SY, et al. Preliminary results of a randomized study on therapeutic gain by concurrent chemotherapy for regionally-advanced nasopharyngeal carcinoma: NPC-9901 Trial by the Hong Kong Nasopharyngeal Cancer Study Group. J Clin Oncol. 2005;23:6966-6975.

3. Wee J, Tan EH, Tai BC, et al. Randomized trial of radiotherapy versus concurrent chemoradiotherapy followed by adjuvant chemotherapy in patients with American Joint Committee on Cancer/International Union against cancer stage III and IV nasopharyngeal cancer of the endemic variety. J Clin Oncol. 2005;23:6730-6738.

4. Kwong DL, Sham JS, Au GK, et al. Concurrent and adjuvant chemotherapy for nasopharyngeal carcinoma: a factorial study. J Clin Oncol. 2004;22:2643-2653.

5. Lin JC, Jan JS, Hsu CY, Liang WM, Jiang RS, Wang WY. Phase III study of concurrent chemoradiotherapy versus radiotherapy alone for advanced nasopharyngeal carcinoma: positive effect on overall and progression-free survival. J Clin Oncol. 2003;21:631-637.

6. Chan AT. Nasopharyngeal carcinoma. Ann Oncol. 2002;21(Suppl 7): vii308-312.

7. Wang WY, Twu CW, Chen HH, et al. Plasma EBV DNA clearance rate as a novel prognostic marker for metastatic/recurrent nasopharyngeal carcinoma. Clin Cancer Res. 2010;16:1016-1024.

8. Al-Sarraf M, Pajak TF, Marcial VA, et al. Concurrent radiotherapy and chemotherapy with cisplatin in inoperable squamous cell carcinoma of the head and neck. An RTOG Study. Cancer. 1987;59:259-265.
9. Al-Sarraf M, Pajak TF, Cooper JS, Mohiuddin M, Herskovic A, Ager PJ. Chemo-radiotherapy in patients with locally advanced nasopharyngeal carcinoma: a radiation therapy oncology group study. J Clin Oncol. 1990;8:1342-1351.

10. Cooper JS, Lee H, Torrey M, Hochster H. Improved outcome secondary to concurrent chemoradiotherapy for advanced carcinoma of the nasopharynx: preliminary corroboration of the intergroup experience. Int J Radiat Oncol Biol Phys. 2000;47:861-866.

11. Chan AT, Teo PM, Ngan RK, et al. Concurrent chemotherapyradiotherapy compared with radiotherapy alone in locoregionally advanced nasopharyngeal carcinoma: progression-free survival analysis of a phase III randomized trial. J Clin Oncol. 2002;20:2038-2044.

12. Chan AT, Leung SF, Ngan RK, et al. Overall survival after concurrent cisplatin-radiotherapy compared with radiotherapy alone in locoregionally advanced nasopharyngeal carcinoma. J Natl Cancer Inst. 2005; 97:536-539.

13. Lee AW, Tung SY, Chan AT, et al. Preliminary results of a randomized study (NPC-9902 Trial) on therapeutic gain by concurrent chemotherapy and/or accelerated fractionation for locally advanced nasopharyngeal carcinoma. Int J Radiat Oncol Biol Phys. 2006;66:142-151.

14. Chen Y, Liu MZ, Liang SB, et al. Preliminary results of a prospective randomized trial comparing concurrent chemoradiotherapy plus adjuvant chemotherapy with radiotherapy alone in patients with locoregionally advanced nasopharyngeal carcinoma in endemic regions of China. Int J Radiat Oncol Biol Phys. 2008;71:1356-1364.

15. Chan AT, Teo PM, Leung TW, et al. A prospective randomized study of chemotherapy adjunctive to definitive radiotherapy in advanced nasopharyngeal carcinoma. Int J Radiat Oncol Biol Phys. 1995;33:569-577.

16. Preliminary results of a randomized trial comparing neoadjuvant chemotherapy (cisplatin, epirubicin, bleomycin) plus radiotherapy vs radiotherapy alone in stage $\operatorname{IV}(>$ or $=\mathrm{N} 2, \mathrm{M} 0)$ undifferentiated nasopharyngeal carcinoma: a positive effect on progression-free survival. International Nasopharynx Cancer Study Group. VUMCA I trial. Int J Radiat Oncol Biol Phys. 1996;35:463-469.

17. Ma J, Mai HQ, Hong MH, et al. Results of a prospective randomized trial comparing neoadjuvant chemotherapy plus radiotherapy with radiotherapy alone in patients with locoregionally advanced nasopharyngeal carcinoma. J Clin Oncol. 2001;19:1350-1357.

18. Chua DT, Sham JS, Choy D, et al. Preliminary report of the AsianOceanian Clinical Oncology Association randomized trial comparing cisplatin and epirubicin followed by radiotherapy versus radiotherapy alone in the treatment of patients with locoregionally advanced nasopharyngeal carcinoma. Asian-Oceanian Clinical Oncology Association Nasopharynx Cancer Study Group. Cancer. 1998;83:2270-2283.

19. Chua DT, Ma J, Sham JS, et al. Long-term survival after cisplatinbased induction chemotherapy and radiotherapy for nasopharyngeal carcinoma: a pooled data analysis of two phase III trials. J Clin Oncol. 2005;23:1118-1124.

20. Hareyama M, Sakata K, Shirato H, et al. A prospective, randomized trial comparing neoadjuvant chemotherapy with radiotherapy alone in patients with advanced nasopharyngeal carcinoma. Cancer. 2002;94:2217-2223.

21. Hui EP, Ma BB, Leung SF, et al. Randomized phase II trial of concurrent cisplatin-radiotherapy with or without neoadjuvant docetaxel and cisplatin in advanced nasopharyngeal carcinoma. J Clin Oncol. 2009;27:242-249.

22. Fountzilas G, Ciuleanu E, Bobos M, et al. Induction chemotherapy followed by concomitant radiotherapy and weekly cisplatin versus the same concomitant chemoradiotherapy in patients with nasopharyngeal carcinoma: a randomized phase II study conducted by the Hellenic Cooperative Oncology Group (HeCOG) with biomarker evaluation. Ann Oncol. 2012;23:427-435.

23. Rossi A, Molinari R, Boracchi P, et al. Adjuvant chemotherapy with vincristine, cyclophosphamide, and doxorubicin after radiotherapy in local-regional nasopharyngeal cancer: results of a 4-year multicenter randomized study. J Clin Oncol. 1988;6:1401-1410. 
24. Chi KH, Chang YC, Guo WY, et al. A phase III study of adjuvant chemotherapy in advanced nasopharyngeal carcinoma patients. Int $J$ Radiat Oncol Biol Phys. 2002;52:1238-1244.

25. Hu W, Ding W, Yang H, et al. Weekly paclitaxel with concurrent radiotherapy followed by adjuvant chemotherapy in locally advanced nasopharyngeal carcinoma. Radiother Oncol. 2009;93:488-491.

26. Chen L, Hu CS, Chen XZ, et al. Concurrent chemoradiotherapy plus adjuvant chemotherapy versus concurrent chemoradiotherapy alone in patients with locoregionally advanced nasopharyngeal carcinoma: a phase 3 multicentre randomised controlled trial. Lancet Oncol. 2012;13:163-171.

27. Zhang L, Zhao C, Ghimire B, et al. The role of concurrent chemoradiotherapy in the treatment of locoregionally advanced nasopharyngeal carcinoma among endemic population: a meta-analysis of the phase III randomized trials. BMC Cancer. 2010;10:558.

28. Baujat B, Audry H, Bourhis J, et al. Chemotherapy in locally advanced nasopharyngeal carcinoma: an individual patient data meta-analysis of eight randomized trials and 1753 patients. Int J Radiat Oncol Biol Phys. 2006;64:47-56.

29. Langendijk JA, Leemans CR, Buter J, Berkhof J, Slotman BJ. The additional value of chemotherapy to radiotherapy in locally advanced nasopharyngeal carcinoma: a meta-analysis of the published literature. J Clin Oncol. 2004;22:4604-4612.

30. Huncharek M, Kupelnick B. Combined chemoradiation versus radiation therapy alone in locally advanced nasopharyngeal carcinoma: results of a meta-analysis of 1,528 patients from six randomized trials. Am J Clin Oncol. 2002;25:219-223.

31. Baujat B, Audry H, Bourhis J, et al; MAC-NPC Collaborative Group. Chemotherapy as an adjunct to radiotherapy in locally advanced nasopharyngeal carcinoma. Cochrane Database Syst Rev. 2006;(4):CD004329.

32. Xia P, Fu KK, Wong GW, Akazawa C, Verhey LJ. Comparison of treatment plans involving intensity-modulated radiotherapy for nasopharyngeal carcinoma. Int J Radiat Oncol Biol Phys. 2000;48: 329-337.

33. Kam MK, Chau RM, Suen J, Choi PH, Teo PM. Intensity-modulated radiotherapy in nasopharyngeal carcinoma: dosimetric advantage over conventional plans and feasibility of dose escalation. Int J Radiat Oncol Biol Phys. 2003;56:145-157.

34. Hunt MA, Zelefsky MJ, Wolden S, et al. Treatment planning and delivery of intensity-modulated radiation therapy for primary nasopharynx cancer. Int J Radiat Oncol Biol Phys. 2001;49:623-632.

35. Wu VW, Kwong DL, Sham JS. Target dose conformity in 3-dimensional conformal radiotherapy and intensity modulated radiotherapy. Radiother Oncol. 2004;71:201-206.

36. Wolden SL, Chen WC, Pfister DG, Kraus DH, Berry SL, Zelefsky MJ. Intensity-modulated radiation therapy (IMRT) for nasopharynx cancer: update of the Memorial Sloan-Kettering experience. Int J Radiat Oncol Biol Phys. 2006;64:57-62.

37. Lee N, Xia P, Quivey JM, et al. Intensity-modulated radiotherapy in the treatment of nasopharyngeal carcinoma: an update of the UCSF experience. Int J Radiat Oncol Biol Phys. 2002;53:12-22.

38. Pow EH, Kwong DL, McMillan AS, et al. Xerostomia and quality of life after intensity-modulated radiotherapy vs conventional radiotherapy for early-stage nasopharyngeal carcinoma: initial report on a randomized controlled clinical trial. Int J Radiat Oncol Biol Phys. 2006;66:981-991.

39. Kwong DL, Pow EH, Sham JS, et al. Intensity-modulated radiotherapy for early-stage nasopharyngeal carcinoma: a prospective study on disease control and preservation of salivary function. Cancer. 2004;101:1584-1593.

40. Lee N, Harris J, Garden AS, et al. Intensity-modulated radiation therapy with or without chemotherapy for nasopharyngeal carcinoma: radiation therapy oncology group phase II trial 0225. J Clin Oncol. 2009;27:3684-3690.

41. Bonner JA, Harari PM, Giralt J, et al. Radiotherapy plus cetuximab for squamous-cell carcinoma of the head and neck. $N$ Engl J Med. 2006;354:567-578.
42. Chan AT, Hsu MM, Goh BC, et al. Multicenter, phase II study of cetuximab in combination with carboplatin in patients with recurrent or metastatic nasopharyngeal carcinoma. J Clin Oncol. 2005;23:3568-3576.

43. Ma BB, Kam MK, Leung SF, et al. A phase II study of concurrent cetuximab-cisplatin and intensity-modulated radiotherapy in locoregionally advanced nasopharyngeal carcinoma. Ann Oncol. 2012;23: 1287-1292.

44. Razak AR, Siu LL, Le Tourneau C. Molecular targeted therapies in all histologies of head and neck cancers: an update. Curr Opin Oncol. 2010;22:212-220.

45. Krishna SM, James S, Balaram P. Expression of VEGF as prognosticator in primary nasopharyngeal cancer and its relation to EBV status. Virus Res. 2006;115:85-90.

46. Xiao X, Wu J, Zhu X, et al. Induction of cell cycle arrest and apoptosis in human nasopharyngeal carcinoma cells by ZD6474, an inhibitor of VEGFR tyrosine kinase with additional activity against EGFR tyrosine kinase. Int J Cancer. 2007;121:2095-2104.

47. Lee NY, Zhang Q, Pfister DG, et al. Addition of bevacizumab to standard chemoradiation for locoregionally advanced nasopharyngeal carcinoma (RTOG 0615): a phase 2 multi-institutional trial. Lancet Oncol. 2012;13:172-180.

48. Widesott L, Pierelli A, Fiorino C, et al. Intensity-modulated proton therapy versus helical tomotherapy in nasopharynx cancer: planning comparison and NTCP evaluation. Int J Radiat Oncol Biol Phys. 2008;72:589-596.

49. Brown AP, Urie MM, Chisin R, Suit HD. Proton therapy for carcinoma of the nasopharynx: a study in comparative treatment planning. Int $J$ Radiat Oncol Biol Phys. 1989;16:1607-1614.

50. Taheri-Kadkhoda Z, Bjork-Eriksson T, Nill S, et al. Intensity-modulated radiotherapy of nasopharyngeal carcinoma: a comparative treatment planning study of photons and protons. Radiat Oncol. 2008;3:4.

51. van de Water TA, Bijl HP, Schilstra C, Pijls-Johannesma M, Langendijk JA. The potential benefit of radiotherapy with protons in head and neck cancer with respect to normal tissue sparing: a systematic review of literature. Oncologist. 2011;16:366-377.

52. Bhide SA, Davies M, Burke K, et al. Weekly volume and dosimetric changes during chemoradiotherapy with intensity-modulated radiation therapy for head and neck cancer: a prospective observational study. Int J Radiat Oncol Biol Phys. 2010;76:1360-1368.

53. Zhao L, Wan Q, Zhou Y, Deng X, Xie C, Wu S. The role of replanning in fractionated intensity modulated radiotherapy for nasopharyngeal carcinoma. Radiother Oncol. 2011;98:23-27.

54. Henle W, Henle G, Ho HC, et al. Antibodies to Epstein-Barr virus in nasopharyngeal carcinoma, other head and neck neoplasms, and control groups. J Natl Cancer Inst. 1970;44:225-231.

55. Xu J, Wan XB, Huang XF, et al. Serologic antienzyme rate of Epstein-Barr virus DNase-specific neutralizing antibody segregates TNM classification in nasopharyngeal carcinoma. J Clin Oncol. 2010;28:5202-5209.

56. Fan H, Nicholls J, Chua D, et al. Laboratory markers of tumor burden in nasopharyngeal carcinoma: a comparison of viral load and serologic tests for Epstein-Barr virus. Int J Cancer. 2004;112:1036-1041.

57. Shao JY, LiYH, Gao HY, et al. Comparison of plasma Epstein-Barr virus (EBV) DNA levels and serum EBV immunoglobulin A/virus capsid antigen antibody titers in patients with nasopharyngeal carcinoma. Cancer. 2004;100:1162-1170.

58. Neel HB 3rd, Taylor WF. Epstein-Barr virus-related antibody. Changes in titers after therapy for nasopharyngeal carcinoma. Arch Otolaryngol Head Neck Surg. 1990;116:1287-1290.

59. Yip TT, Ngan RK, Lau WH, et al. A possible prognostic role of immunoglobulin-G antibody against recombinant Epstein-Barr virus BZLF-1 transactivator protein ZEBRA in patients with nasopharyngeal carcinoma. Cancer. 1994;74:2414-2424.

60. Twu CW, Wang WY, Liang WM, et al. Comparison of the prognostic impact of serum anti-EBV antibody and plasma EBV DNA assays in nasopharyngeal carcinoma. Int J Radiat Oncol Biol Phys. 2007; 67:130-137 
61. de-Vathaire F, Sancho-Garnier H, de-The H, et al. Prognostic value of EBV markers in the clinical management of nasopharyngeal carcinoma (NPC): a multicenter follow-up study. Int J Cancer. 1988;42: 176-181.

62. Lo YM, Chan AT, Chan LY, et al. Molecular prognostication of nasopharyngeal carcinoma by quantitative analysis of circulating Epstein-Barr virus DNA. Cancer Res. 2000;60:6878-6881.

63. Lo YM, Leung SF, Chan LY, et al. Plasma cell-free Epstein-Barr virus DNA quantitation in patients with nasopharyngeal carcinoma. Correlation with clinical staging. Ann N Y Acad Sci. 2000;906: 99-101.

64. Ma BB, King A, Lo YM, et al. Relationship between pretreatment level of plasma Epstein-Barr virus DNA, tumor burden, and metabolic activity in advanced nasopharyngeal carcinoma. Int J Radiat Oncol Biol Phys. 2006;66:714-720.

65. Leung SF, Chan AT, Zee B, et al. Pretherapy quantitative measurement of circulating Epstein-Barr virus DNA is predictive of posttherapy distant failure in patients with early-stage nasopharyngeal carcinoma of undifferentiated type. Cancer. 2003;98:288-291.

66. Leung SF, Zee B, Ma BB, et al. Plasma Epstein-Barr viral deoxyribonucleic acid quantitation complements tumor-node-metastasis staging prognostication in nasopharyngeal carcinoma. J Clin Oncol. 2006;24:5414-5418.

67. Lin JC, Wang WY, Chen KY, et al. Quantification of plasma EpsteinBarr virus DNA in patients with advanced nasopharyngeal carcinoma. $N$ Engl J Med. 2004;350:2461-2470.

68. Chan AT, Lo YM, Zee B, et al. Plasma Epstein-Barr virus DNA and residual disease after radiotherapy for undifferentiated nasopharyngeal carcinoma. J Natl Cancer Inst. 2002;94:1614-1619.

69. Wang WY, Twu CW, Lin WY, et al. Plasma Epstein-Barr virus DNA screening followed by (1)F-fluoro-2-deoxy-D-glucose positron emission tomography in detecting posttreatment failures of nasopharyngeal carcinoma. Cancer. 2011;117:4452-4459.
70. Pan JJ, Zhang SW, Chen CB, et al. Effect of recombinant adenovirusp53 combined with radiotherapy on long-term prognosis of advanced nasopharyngeal carcinoma. J Clin Oncol. 2009;27:799-804.

71. Zhang L, Zhao C, Peng PJ, et al. Phase III study comparing standard radiotherapy with or without weekly oxaliplatin in treatment of locoregionally advanced nasopharyngeal carcinoma: preliminary results. J Clin Oncol. 2005;23:8461-8468.

72. Kam MK, Teo PM, Chau RM, et al. Treatment of nasopharyngeal carcinoma with intensity-modulated radiotherapy: the Hong Kong experience. Int J Radiat Oncol Biol Phys. 2004;60:1440-1450.

73. Tham IW, Hee SW, Yeo RM, et al. Treatment of nasopharyngeal carcinoma using intensity-modulated radiotherapy-the National Cancer Centre Singapore experience. Int J Radiat Oncol Biol Phys. 2009;75: 1481-1486.

74. Lin S, Pan J, Han L, Zhang X, Liao X, Lu JJ. Nasopharyngeal carcinoma treated with reduced-volume intensity-modulated radiation therapy: report on the 3-year outcome of a prospective series. Int J Radiat Oncol Biol Phys. 2009;75:1071-1078.

75. Wong FC, $\mathrm{Ng} \mathrm{AW}$, Lee VH, et al. Whole-field simultaneous integratedboost intensity-modulated radiotherapy for patients with nasopharyngeal carcinoma. Int J Radiat Oncol Biol Phys. 2010;76:138-145.

76. Ng WT, Lee MC, Hung WM, et al. Clinical outcomes and patterns of failure after intensity-modulated radiotherapy for nasopharyngeal carcinoma. Int J Radiat Oncol Biol Phys. 2010;79:420-428.

77. Xiao WW, Huang SM, Han F, et al. Local control, survival, and late toxicities of locally advanced nasopharyngeal carcinoma treated by simultaneous modulated accelerated radiotherapy combined with cisplatin concurrent chemotherapy: long-term results of a phase 2 study. Cancer. 2011;117:1874-1883.

78. Lai SZ, Li WF, Chen L, et al. How does intensity-modulated radiotherapy versus conventional two-dimensional radiotherapy influence the treatment results in nasopharyngeal carcinoma patients? Int J Radiat Oncol Biol Phys. 2011;80:661-668.
OncoTargets and Therapy

\section{Publish your work in this journal}

OncoTargets and Therapy is an international, peer-reviewed, open access journal focusing on the pathological basis of all cancers, potential targets for therapy and treatment protocols employed to improve the management of cancer patients. The journal also focuses on the impact of management programs and new therapeutic agents and protocols on

\section{Dovepress}

patient perspectives such as quality of life, adherence and satisfaction The manuscript management system is completely online and includes a very quick and fair peer-review system, which is all easy to use. Visit http://www.dovepress.com/testimonials.php to read real quotes from published authors. 